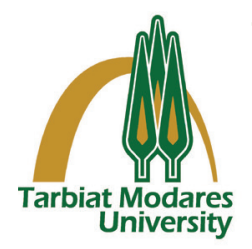

\title{
Agr Typing and Detection of Mupirocin Resistance in Multi-Drug Resistant Clinical Isolates of Staphylococcus aureus in Northern Iran
}

\section{ART I CLE INF O}

Article Type

Original Research

Authors

Leila Asadpour, $P h D^{1^{*}}$

Elham Jafarnejhad, $M S c^{1}$

Amineh Abdi, $M S c^{1}$

\section{How to cite this article}

Asadpour L., Jafarnejhad E., Abdi

A. Agr Typing and Detection of

Mupirocin Resistance in Multi-

Drug Resistant Clinical Isolates of

Staphylococcus aureus in Northern

Iran. Infection Epidemiology and

Microbiology. 2021;7(3): 197-205

${ }^{1}$ Department of Biology, Rasht Branch, Islamic Azad University, Rasht, Iran

\section{* Correspondence}

Address: Department of Biology, Rasht Branch, Islamic Azad University, Rasht, Iran.

Asadpour@iaurasht.ac.ir

\begin{abstract}
A B S T R A C T
Background: Mupirocin is a topical antibiotic inhibiting most Gram-positive cocci. Shortly after taking mupirocin, drug resistance emerges. This study aimed to determine mupirocin resistance in Staphylococcus aureus strains isolated from clinical specimens in Rasht.

Materials \& Methods: In this study, a total of 85 clinical isolates of $S$. aureus were collected. Biofilm formation ability and antibacterial resistance patterns of isolates were investigated. Disc diffusion method and MIC determination were used to determine the susceptibility of strains to mupirocin antibiotic. Agr types, the presence of mupA, and mutation in ileS-1 were evaluated in mupirocin non-susceptible isolates by PCR and PCR sequencing, respectively. Findings: Out of 85 tested strains, 57 (67\%) isolates were recognized as biofilm producers, and all of which showed multidrug resistance phenotype. Agr type 1 was the most commonly detected type. Additionally, 12 mupirocin-resistant strains were identified in the disc diffusion and MIC tests. A total of four strains were mup-A positive and showed high-level resistance. In sequencing and mutation evaluation of the ileS-1 gene in eight low-level mupirocin-resistant strains, 12 types of silent mutation and one type of missense mutation were determined.

Conclusion: The study of mupirocin-resistant strains in this study showed the need to identify factors affecting the occurrence of resistance and to take control and prevention measures before mupirocin losses its efficacy.
\end{abstract}

\section{Keywords: Staphylococcus aureus, Mupirocin resistance, ileS-1, MupA.}

\section{CITATION LINKS}

[1] Goudarzi M, Fazeli M, Eslami G, Pouriran R. Genetic diversity analysis of ... [2] David MZ, Daum RS. Community-associated ... [3] Wertheim HF, Melles DC, Vos MC, Leeuwen W, Belkum A. The role of nasal... [4] Nakama T, Nureki O, Yokoyama S. Structural basis for ... [5] Matthijs S, Vander Wauven C, Cornu B, Ye L, Cornelis P, Thomas CM, et al. Antimicrobial ... [6] Chen S, Jin Y, Lin C, Hao Z, Duan J, Guo Y, et al. Low prevalence ... [7] Driscoll DG, Young CL, Ochsner UA. Transient loss of high-level mupirocin ... [8] Seah C, Louie L, Simor A, Donald E, Roberto G. MupB, a new ... [9] Godbeer MS, Gold RM, Lawhon SD. Prevalence of ... [10] Mahmoudi S, Mamishi S, Mohammadi M, Banar M, Ashtiani MT, Mahzari M, et al. Phenotypic and genotypic determinants of mupirocin resistance among Staphylococcus aureus isolates recovered from ... [11] Javdan S, Narimani T, Abadi MS, Gholipour A. Agr typing of ... [12] Bibalan MH, Shakeri F, Javid N, Ghaemi A, Ghaemi EA. Accessory gene ... [13] Paniagua-Contreras G, Sáinz-Espuñes T, Monroy-Pérez E, Rodríguez-Moctezuma JR, Arenas-Aranda D, Negrete-Abascal E, et al. Virulence markers in Staphylococcus aureus strains isolated from ... [14] Cha JO, Yoo JI, Yoo JS, Chung HS, Park SH, Kim HS, et al. Investigation of ... [15] Magiorakos AP, Srinivasan A, Carey RT, Carmeli Y, Falagas MT, Giske CT, et al. Multidrug-resistant, extensively ... [16] Grinholc M, Nakonieczna J, Negri A, Rapacka-Zdonczyk A, Motyka A, Fila G, et al. The agr ... [17] Mohajeri P, Gholamine B, Rezaei M, Khamisabadi Y. Frequency of mupirocin ... [18] Orrett FA. The emergence of mupirocin resistance among clinical ... [19] Fujimura S, Tokue Y, Watanabe A. IsoleucyltRNA synthetase mutation in ... [20] Antonio M, McFerran N, Pallen MJ. Mutations affecting the Rossman fold of ... [21] Yang JA, Park DW, Sohn JW, Yang IS, Kim KH, Kim MJ. Molecular analysis of ... [22] Hesami S, Hosseini SD, Amouzandeh-Nobaveh A, Eskandari S, GhaznaviRad E. Phenotypic and genotypic determination of mupirocin resistance among methicillin susceptibility and ... [23] Daskalaki M, Otero JR, Chaves F. Molecular characterization of ... [24] Chaturvedi P, Singh AK, Shukla S, Agarwal L. Prevalence of ... [25] Saderi H, Oulia P, Habibi M. Detection of resistance to mupirocin in Staphylococcus aureus strains isolated from patients in four university hospitals of Tehran by polymerase chain reaction (pcr) method. Daneshvar Med: Basic Clin Res ... [26] Hadadi M, Heidari H, Ebrahim-Saraie HS, Motamedifar M. Molecular characterization of vancomycin, mupirocin, and antiseptic resistant Staphylococcus aureus strains. Mediterr J Hematol ... 


\section{Introduction}

Staphylococcus aureus is a microbial flora of the skin and nasal passages of some people and one of the most common pathogens responsible for a wide range of infections from superficial skin infections to many serious infections such as septicemia, endocarditis, and osteomyelitis in hospitalized patients. Drug resistance is more common in S. aureus strains than other bacteria ${ }^{[1-2]}$. Mupirocin is one of the most effective antibiotics against Gram-positive cocci, used as a topical antimicrobial agent [3]. Nowadays, this antibiotic is used to prevent or treat skin surface infections, such as yellow ulcers, wound, and burn infections, and remove $S$. aureus nasal carriers and control MRSA transmission in healthcare settings ${ }^{[1,4]}$. Mupirocin is a polyketide antibiotic with broad-spectrum antibacterial effects. Mupirocin epoxide side chain has a structure similar to isoleucine and could be linked to a specific position of isoleucine in isoleucine-tRNA synthetase and inhibit this enzyme and prevent the synthesis of protein and RNA, leading to bacterial death [5]. However, increased use of mupirocin causes the development of mupirocin resistance among $S$. aureus isolates. The development of resistance to mupirocin could be of both chromosomal and plasmid origins and is phenotypically divided into low- and high-level mupirocin resistance ${ }^{[6-7]}$. Low-level resistance appears due to decreased sensitivity to mupirocin as a result of mutation in chromosomal ileS-1 gene encoding isoleucine-tRNA synthetase [7]. This type of resistance is sustainable and could be transferred to the next generation ${ }^{[8]}$. High-level resistance, which is a major threat to the clinical use of mupirocin, occurs due to the acquisition of plasmid-borne resistance genes including mupA (also known as ileS2) and $\operatorname{mupB}$, both of which encode an alternative isoleucine-tRNA synthetase
[9-10]. Conjugation of transgenic plasmids expressing this protein has been proven in staphylococcal strains in vitro and in vivo. It is believed that this plasmid transfer could contribute to the development of mupirocin resistance. The mupB gene encoding plasmid is responsible for very high-level mupirocin resistance ${ }^{[7]}$.

The accessory gene regulator $(a g r)$ is one of the major factors regulating and controlling cell surface proteins and virulence gene expression in $S$. aureus strains. The agr operon includes agrA, $\operatorname{agr} B, \operatorname{agrC}$, and $\operatorname{agr} D$ genes. Agr system is polymorphic and permits the classification of $S$. aureus strains into four groups (agr I, agr II, agr III, and agr IV) according to sequences diversity in variable regions, comprising the last third of $\operatorname{agr} B$ and $a g r D$ as well as the first half of $\operatorname{agrC}$ genes [11-12].

Objectives: The aim of this study was to evaluate agr types and mupirocin resistance in clinical isolates of $S$. aureus in Guilan province.

\section{Materials and Methods}

Test bacteria: $S$. aureus isolates were collected from hospitalized patients in Rasht during 2018. To isolate test bacteria, samples were cultured on mannitol salt agar and blood agar (Merck, Germany). Different biochemical characteristics including coagulase, catalase, and DNase production were investigated in the isolates. Subsequently, the identification of $S$. aureus isolates was confirmed by a pair of 23SrRNA specific primers via PCR as described previously [13].

Biofilm formation assay: This assay was performed in a microtiter plate. Overnight cultures of $S$. aureus isolates $\left(1.5 \times 10^{8}\right.$ $\mathrm{CFU} / \mathrm{mL})$ were diluted $(1: 100)$ in brain heart infusion broth supplemented with $1 \%$ glucose. Then $200 \mu \mathrm{L}$ of each bacterial suspension was transferred into each well 
of a 96-well flat-bottom polystyrene plate and incubated at $37{ }^{\circ} \mathrm{C}$ for 48 hours. After incubation, the plank tonic bacteria were removed, wells were gently rinsed three times with sterile physiological saline and fixed by methanol for $20 \mathrm{~min}$. Subsequently, the cells attaching to the surface were stained with crystal violet and rewashed. Then the assay was followed by destaning of biofilm-associated crystal violet using $1 \mathrm{~mL}$ of ethanol-acetone (95:5, vol/vol) solution. Subsequently, the optical density of the mixed solution was measured at $\mathbf{5 7 0}$ $\mathrm{nm}$. The isolates were divided into three categories according their ability to produce biofilm as follows: non-biofilm producer $\left(\mathrm{OD}_{570}<0.2\right)$, weak-biofilm producer $\left(0.2<\mathrm{OD}_{570}<\right.$ 1.0)and strong-biofilm producer $\left(\mathrm{OD}_{570}>1.0\right)^{[14]}$. Antibacterial resistance: Antibacterial resistance of $S$. aureus isolates was investigated using the disc diffusion method according to the CLSI guideline. The antibiotic disks used in this study (High Media-India) included clindamycin $(2 \mu \mathrm{g})$, gentamicin (10 $\mu \mathrm{g})$, teicoplanin $(30 \mu \mathrm{g})$, linezolid $(30 \mu \mathrm{g})$, mupirocin $(20 \mu \mathrm{g})$, co-trimoxazole $(23.75$ $\mu \mathrm{g})$, ciprofloxacin $(5 \mu \mathrm{g})$, erythromycin $(15$ $\mu \mathrm{g})$, cephalexin $(30 \mu \mathrm{g})$, cephalothin (30 $\mu \mathrm{g})$, methicillin $(5 \mu \mathrm{g})$, amoxicillin $(25 \mu \mathrm{g})$, amoxiclav $(30 \mu \mathrm{g})$, and penicillin $\mathrm{G}$. The tests were repeated twice, and bacterial resistance or susceptibility to antibiotics was determined by measuring the inhibition zone diameter according to the CLSI guideline. In addition, susceptibility to vancomycin was assessed by MIC determination based on the CLSI guideline (CLSI, 2018). The standard strain of $S$. aureus ATCC 33591 was used as control. S. aureus isolates resistant to at least three antimicrobial classes were considered as multidrug resistant (MDR) [15].

Agr typing: Agr gene types were determined by agr group-specific multiplex PCR using primers specific to four types of this gene as described previously ${ }^{[12]}$. PCR reaction was perform in a total volume of $25 \mu \mathrm{L}$, including $0.5 \mu \mathrm{L}$ of dNTPs $(10 \mu \mathrm{M}), 5 \mu \mathrm{L}$ of enzyme buffer (10X), $1 \mu \mathrm{L}$ of each $(8 \mu \mathrm{L}$ in total) reverse and forward primers (10 pM), $2 \mu \mathrm{L}$ of template DNA ( $2 \mu \mathrm{g}), 0.5 \mu \mathrm{L}$ of Taq polymerase enzyme (2.5 units) (Bioneer, South Korea), and $9 \mu \mathrm{L}$ of distilled water. Thermocycler thermal conditions consisted of an initial denaturation step at $94^{\circ}$ for 5 min, followed by 30 cycles of denaturation at $94{ }^{\circ} \mathrm{C}$ for $30 \mathrm{~s}, 55^{\circ} \mathrm{C}$ for $30 \mathrm{~s}$, and $72{ }^{\circ} \mathrm{C}$ for $60 \mathrm{~s}$. Then a final extension step at 72 ${ }^{\circ} \mathrm{C}$ for 10 min was included. PCR products were detected by electrophoresis using a 1\% agarose gel and confirmed by sequencing. Identification of mupirocin resistant strains: Mupirocin resistance was determined using a standard disc diffusion method and determination of MIC by broth microdilution method (CLSI, 2018).

Amplification of iles-1, mupA, and mupB genes: To amplify ileS-1 and mupA genes, two pairs of primers specific to these genes were used. Table 1 shows the nucleotide sequences of these primers. The PCR reaction was carried out in a total volume of $25 \mu \mathrm{L}$ consisting of $0.5 \mu \mathrm{L}$ of dNTPS (10 $\mu \mathrm{M}), 5 \mu \mathrm{L}$ of enzyme buffer (10x), $1.5 \mu \mathrm{L}$ of each reverse and forward primers $(10 \mathrm{pM})$, $2 \mu \mathrm{L}$ of template DNA ( $2 \mu \mathrm{g}), 0.5 \mu \mathrm{L}$ of $P f u$ enzyme (2.5 units) (Bioneer, South Korea), and $14 \mu \mathrm{L}$ of distilled water. Thermocycler thermal conditions consisted of an initial denaturation step at $94^{\circ} \mathrm{C}$ for $5 \mathrm{~min}$, followed by 30 cycles of denaturation at $94{ }^{\circ} \mathrm{C}$ for 45 $\mathrm{s}$, annealing according to table 1 for $45 \mathrm{~s}$ and $72{ }^{\circ} \mathrm{C}$ for $60 \mathrm{~s}$. Then a final extension step at $72{ }^{\circ} \mathrm{C}$ for $10 \mathrm{~min}$ was included. PCR products were detected by electrophoresis using a $1 \%$ agarose gel, and one PCR product from each type was confirmed by sequencing ${ }^{[10,17]}$.

Investigation of mutation of iles-1 gene: After assuring the production of the desired product, it was sent to Bioneer Company (South Korea) for sequencing. Nucleotide 
Table 1) Oligonucleotide primers used for the amplification of particular sequences of $S$. aureus mup $A$, mupB, and ileS-1 genes

\begin{tabular}{|c|c|c|c|c|}
\hline Gene & Primer Sequence & $\begin{array}{l}\text { Amplicon } \\
\text { Size (bp) }\end{array}$ & $\begin{array}{l}\text { Annealing } \\
\text { Tem. }\left({ }^{\circ} \mathrm{C}\right)\end{array}$ & Ref. \\
\hline $\operatorname{Agr} 1-F$ & 5'-ATG CAC ATG GTG CAC ATG C-3' & \multirow{2}{*}{441} & \multirow{2}{*}{56} & \multirow{2}{*}{16} \\
\hline Agr1-R & 5'-GTC ACA AGT ACT ATA AGC GCT GAT-3' & & & \\
\hline $\operatorname{Agr} 2-F$ & 5'-ATG CAC ATG GTG CAC ATG C-3' & \multirow{2}{*}{575} & \multirow{2}{*}{56} & \multirow{2}{*}{16} \\
\hline $\operatorname{Agr} 2-R$ & 5'-TAT TAC TAA TTG AAA AGT GGC CAT AGC-3' & & & \\
\hline Agr3-F & 5'-ATG CAC ATG GTG CAC ATG C-3' & \multirow{2}{*}{323} & \multirow{2}{*}{56} & \multirow{2}{*}{16} \\
\hline $\operatorname{Agr} 3-R$ & 5'-GTA ATG TAA TAG CTT GTA TAA TAA TAC CCA G-3' & & & \\
\hline $\operatorname{Agr} 4-F$ & 5'-ATG CAC ATG GTG CAC ATG C-3' & \multirow{2}{*}{659} & \multirow{2}{*}{56} & \multirow{2}{*}{16} \\
\hline Agr4-R & 5'-CGA TAA TGC CGT AAT CG-3' & & & \\
\hline mupA-F & $5^{\prime}$-TAAGGAAGGGAGAATGGGAA $-3^{\prime}$ & \multirow{2}{*}{456} & \multirow{2}{*}{60} & \multirow{2}{*}{17} \\
\hline mupA-R & 5'-CTGAGCAAACGGCATAGAGC -3' & & & \\
\hline $\operatorname{mup} B-F$ & 5'-CTAGAAGTCGATTTTGGAGTAG-3' & \multirow{2}{*}{674} & \multirow{2}{*}{60} & \multirow{2}{*}{10} \\
\hline $\operatorname{mup} B-R$ & 5'-AGTGTCTAAAATGATAAGACGATC-3' & & & \\
\hline iles-1-F & 5'-CAGTTGCTACAAGAGGAGTGTCACC-3' & \multirow{2}{*}{915} & \multirow{2}{*}{65} & \multirow{2}{*}{17} \\
\hline iles-1- $R$ & 5'-CACCATGTTCATAAGCTGTTGCC -3’ & & & \\
\hline
\end{tabular}

sequences of the isolated strains ileS-1 gene were compared to that of standard strain of $S$. aureus in gene bank, and changes in base and amino acid sequences were determined using online software, such as BLAST, Chromas (Ver. 1.45), and CLC Main Workbench (Ver.3.5).

\section{Findings}

Identification of $S$. aureus and biofilm formation ability: Totally, $85 \mathrm{~S}$. aureus strains were isolated. Distribution of $S$. aureus isolates according to the type of samples was as follows: 45 isolates from urine and 40 isolates from wound and abscess. According to amplification of the 23s rRNA gene, all 85 isolates were confirmed as $S$. aureus. In phenotypic assays, 57 isolates (67\%) were recognized as biofilm producers: 19 strong and 38 weak biofilm producers; the others $(28$ isolates) did not form biofilm.
Antibacterial resistance pattern: All the tested isolates showed multidrug resistance phenotype. Resistance rate of $S$. aureus isolates to 14 selected antibiotics was as follows: clindamycin, 6 (7.05\%); gentamicin, 8 (9.41\%); vancomycin, 3 (3.53\%); teicoplanin, 4 (4.7\%); linezolid, 5 (5.9\%); methicillin, 53 (62.35\%); co-trimoxazole, 32 (37.64\%); ciprofloxacin, 38 (44.7\%); erythromycin, 44 (51.76\%); cephalexin, 49 (57.64\%); cephalothin, 35 (41.17\%); amoxicillin, 51 (50.59\%); amoxiclav, 26 (30.59\%); and penicillin G, 80 (94.12\%). Agr typing: Among the 85 isolates studied, agr gene was identified in $81 \mathrm{~S}$ aureus isolates using primers specific to four types of this gene. A total of 65 isolates (76.5\%) were identified as agr type 1, eight isolates (9.4\%) as agr type 2, five isolates (5.9\%) as agr type 3, and three isolates (3.5\%) as agr type 4 . None of the agr types were detected in four isolates. 
Table 2) Drug resistance patterns of mupirocin non-susceptible isolates

\begin{tabular}{lll}
\hline $\begin{array}{l}\text { Bacterial } \\
\text { Isolate }\end{array}$ & $\begin{array}{l}\text { Mupirocin } \\
\text { Resistance Level }\end{array}$ & Drug Resistance Pattern \\
\hline 1 & Low & E, TET, CP, SXT, FOX, CFX, PEN, MET, AMX, AMC \\
\hline 2 & Low & CC, GM, E, TET, CP, CFX, PEN, MET \\
\hline 3 & Low & E, LZD, TET, CP, SXT, FOX, CFX,PEN, MET, AMX, AMC \\
\hline 4 & Low & E, TET, CP, SXT, FOX, CFX, PEN, MET, AMX, AMC \\
\hline 5 & Low & GM, TEK, TET, CFX, PEN, V, MET, AMX \\
\hline 6 & Low & E, CP, CFX, PEN, MET, AMX, AMC \\
\hline 7 & Low & E, TET, SXT, FOX, CFX, PEN, MET, AMX, AMC \\
\hline 9 & Low & GM, E, TET, SXT, FOX, CFX, PEN, MET, AMX, AMC \\
\hline 10 & High & CC, E, TET, CP, SXT, CFX, PEN, MET, AMX \\
\hline 11 & High & E, LZD, TEK, TET,CP, FOX, CFX, PEN, V, MET, AMX \\
\hline 12 & High & CC, GM, E, LZD, TET, CP, SXT, FOX, CFX, PEN, MET \\
\hline High & CC, GM, E, TEK, TET, SXT, FOX, CFX, PEN, V, MET, AMX, AMC \\
\hline
\end{tabular}

CC: clindamycin, GM: gentamicin, E: erythromycin, LZD: linezolid, TEK: teicoplanin, TET: Tetracyclin, CP: ciprofloxacin, SXT: trimethoprim-sulfamethoxazole, FOX: cefoxitin, CFX: cephalexin PEN: penicillin, V: vancomycin, MET: methicillin, AMX: amoxicillin, and AMC: amoxiclav.

Detection of mupirocin resistant strains: In the phenotypic assay, eight isolates with a mupirocin MIC of $8-128 \mu \mathrm{g} / \mathrm{mL}$ were identified as low-level mupirocin resistant strains, and four isolates with MIC of $512 \mu \mathrm{g} / \mathrm{mL}$ were recognized as highlevel resistant strains. All of the mupirocin non-susceptible isolates were methicillin resistant and belonged to agr type 1 . Linezolid was the most potent antibiotic against mupirocin resistant strains. Table 2 presents antibacterial drug resistance patterns in mupirocin non-susceptible $S$. aureus isolates.

Detection of mupA and mupB genes: Using mupA gene specific primers in PCR, a PCR product with an approximate length of $456 \mathrm{bp}$ was obtained in four isolates (5.9\%) with a MIC of $512 \mu \mathrm{g} / \mathrm{mL}$. All of low-level mupirocin-resistant strains were negative for mupA gene. All of mupA positive strains were biofilm producer in the phenotypic assay. None of the tested isolates harbored the mupB gene.

Investigation of mutation of iles-1 gene: PCR amplification of the ileS-1 gene in eight low-level mupirocin-resistant strains resulted in 915 bp amplicons. Comparing the nucleoside sequences of the isolates ileS1 gene with that of $S$. aureus standard strain in the gene bank, one type of mutation was detected in three isolates. This mutation resulted in replacing E707 with G, leading to the replacement of glutamic acid with glycine. Furthermore, 12 different silent mutations were identified in this investigation. Table 3 presents the obtained results for each isolate.

\section{Discussion}

Mupirocin was first introduced in 1985 in the United Kingdom; in 1986, it was used in hospitals (SFGH) to eradicate methicillin resistant $S$. aureus (MRSA) and intrinsic 
Table 3) MIC of mupirocin, biofilm formation ability, and mutations in the ileS-1 gene in low-level mupirocinresistant $S$, aureus isolates

\begin{tabular}{llllll}
\hline $\begin{array}{l}\text { Bacterial } \\
\text { Isolate }\end{array}$ & $\begin{array}{l}\text { Sample } \\
\text { Type }\end{array}$ & $\begin{array}{l}\text { Biofilm } \\
\text { Formation }\end{array}$ & $\begin{array}{l}\text { Mupirocin } \\
\text { MIC }(\mu \mathrm{g} / \mathbf{m L})\end{array}$ & $\begin{array}{l}\text { Missense Mutation } \\
\text { Wound }\end{array}-\begin{array}{llll}\text { Number of Silent } \\
\text { Mutations }\end{array}$ \\
\hline 2 & Woun & 8 & - & 7 \\
\hline 3 & Abscess & + & 32 & - & 6 \\
\hline 4 & Urine & - & 64 & E707G & 8 \\
\hline 5 & Wound & + & 128 & - & 9 \\
\hline 6 & Abscess & + & 128 & - & 8 \\
\hline 7 & Wound & + & 128 & E707G & 7 \\
\hline 8 & Urine & + & 128 & E707G & 7 \\
\hline
\end{tabular}

methicillin sensitive S. aureus (MSSA) strains. Two years after introducing mupirocin, the first case of mupirocin resistance was reported, and since then, various types of resistance have been reported ${ }^{[18]}$.

The present study determined agr types, biofilm formation ability, antibacterial resistance pattern, and mupirocin resistance mechanisms in $S$. aureus strains isolated from clinical specimens collected from Rasht hospitals, northern Iran. In this assay, all of the tested strains were multidrug resistant. The highest resistance rate was against penicillin G, followed by methicillin and cephalexin. Vancomycin, linezolid, and ticoplanin were the most potent antibiotics. Moreover, 67\% of these isolates were biofilm producers, and agr type 1 was the most common type in these isolates. More than $75 \%$ of the isolates belonged to this type. Predominance of agr type 1 is in accordance with previous data from Iran ${ }^{[11-12]}$. In the phenotypic assay, 12 of 85 isolates tested were mupirocin resistant. All of the mupirocin-resistant strains were methicillin resistant and biofilm producer while belonging to agr type 1; among which, eight isolates were identified as low-level mupirocin resistant. The MIC of mupirocin in these isolates ranged from $8-128 \mathrm{mcg} /$ $\mathrm{mL}$. In 3 of them, E707G single point amino acid substitution was identified. All of these isolates had silent mutations, and totally, 12 different types of silent mutations were recognized. In most cases, the number of mutations in ileS-1 gene was positively correlated with MIC value. E707G amino acid substitution identified in ileS-1 has not been previously reported. In a study conducted by Fujimora et al. (2003), A637G, G1762T, G1891T, and A2412T amino acids substitution in ileS-1 was reported in mupirocin-resistant $S$. aureus strains ${ }^{[19]}$. In a study by Antonio et al. (2002), 22 silent mutations and 9 types of missense mutations, including A110C, T635C, A637G, A769G, G808T, G1891T, T1948A, A2330G, and G1762T, were reported in the ileS-1 gene in $S$. aureus isolates with decreased sensitivity to mupirocin ${ }^{[20]}$.

In addition, Yang et al. (2006) reported that all mupirocin resistant isolates showed mutation at V588F. Furthermore, they reported P187F, K226T, F227L, Q612H, and V767D mutations [21].

Moreover, in the present study, four highlevel mupirocin resistance phenotypes were identified, all of which were positive for mup $A$ gene. MIC of mupirocin was $512 \mu \mathrm{g} / \mathrm{mL}$ in these isolates. In similar studies, Hesami et al. (2013) identified 11 mupirocin-resistant mupA positive isolates [22]. Contrary to the present study, highly resistant isolates had 
a higher prevalence than low-level resistant strains. On the other hand, in a study by Daskalaki et al. (2009) in Spain, out of 23 (11.3\%) mupirocin-resistant isolates, 18 (78.3\%) isolates had high-level resistance, and five isolates (21.7\%) had low-level resistance. All high-level mupirocinresistant isolates were positive for the presence of the ileS-2 gene in PCR reaction, while the isolates with low-level resistance were negative for the presence of this gene ${ }^{[23]}$. In a study by Chaturvedi et al. (2014), out of 15 mupirocin-resistant strains, eight ones (53.3\%) showed high-level resistance, and seven (46.7\%) isolates exhibited low-level resistance [24].

Among mupirocin non-susceptible isolate, four (5.9\%) isolates were identified as high-level mupirocin resistant with a MIC of $\geq 512 \mu \mathrm{g} / \mathrm{mL}$. This frequency was high in comparison with that reported by Mahmoudi et al. (2019), identifying mupirocin resistance in 3\% of clinical isolates of $S$. aureus in Tehran, Iran. In their study, the mupA gene was detected in two out of four high-level mupirocin resistant isolates, and the mupB gene was not detected in any isolates, which is in accordance with the present study results ${ }^{[10]}$. In another study performed in Tehran, the prevalence of lowlevel and high-level mupirocin-resistant isolates as well as the mupA gene was $3.5,1$, and, 5.8\%, respectively ${ }^{[25]}$. A study in Arak reported that the frequency of high-level mupirocin resistance and the mup $A$ gene in isolates was 7.3 and 6\%, respectively ${ }^{[22]}$. Also, in $2018,12.5 \%$ of $S$. aureus clinical isolates from two major hospitals in Shiraz were high-level mupirocin-resistant, and 55 (45.8\%) isolates carried the mupA gene ${ }^{[26]}$.

\section{Conclusion}

Overall, the present study and different studies worldwide indicate the emergence and spread of mupirocin resistance in $S$. aureus isolates. Identification of mupirocinresistant strains highlights the need to identify factors affecting the occurrence of these resistance and to take control and prevention measures before mupirocin losses its efficacy. Therefore, regular surveillance of $S$. aureus strains resistance to this antimicrobial and establishment of adequate infection control measures against resistant isolates are suggested.

Acknowledgments: The authors are grateful to the Islamic Azad University, Rasht Branch, Rasht, Iran for support.

Ethical permission: All applicable international, national, and/or institutional guidelines for the care and use of animals were followed.

Conflicts of interests: The authors declare that there is no conflict of interest.

Authors' contribution: Conceptualization: LA, EJ, AA; Data curation and formal analysis: LA; Funding acquisition: LA, EJ and AA; Investigation: LA, EJ, AA; Methodology and project administration: LA; Resources: LA, EJ and AA; Supervision: LA; Validation: LA; Writing of original draft: LA; Writing, reviewing, and editing: LA.

Fundings: The authors received no specific funding for this work.

Consent to participate: Authors declare that all patients have signed the participation form.

\section{References}

1. Goudarzi M, Fazeli M, Eslami G, Pouriran R. Genetic diversity analysis of mupirocinresistant Staphylococcus aureus clinical isolates in Tehran hospitals, Iran. Microb Drug Resist. 2019;25(4):558-66.

2. David MZ, Daum RS.Community-associated methicillin-resistant Staphylococcus aureus: Epidemiology and clinical consequences of an emerging epidemic. Clin Microbiol Rev 2010;23(3):616-87. 
3. Wertheim HF, Melles DC, Vos MC, Leeuwen $\mathrm{W}$, Belkum A. The role of nasal carriage in Staphylococcus aureus infections. J Lancet Infect Dis. 2005;5(12):751-62.

4. Nakama T, Nureki O, Yokoyama S. Structural basis for the recognition of isoleucyl-adenylate and an antibiotic, mupirocin, by isoleucyl-tRNA synthetase. J Biol Chem. 2001;276(50):47387-93.

5. Matthijs S, Vander Wauven C, Cornu B, Ye L, Cornelis P, Thomas CM, et al. Antimicrobial properties of Pseudomonas strains producing the antibiotic mupirocin. Res Microbiol. 2014;165(8):695-704.

6. Chen S, Jin Y, Lin C, Hao Z, Duan J, Guo $\mathrm{Y}$, et al. Low prevalence of mupirocin resistance among Staphylococcus aureus clinical isolates from a Chinese tertiary hospital. J Med Microbiol. 2019;68(2):201-5.

7. Driscoll DG, Young CL, Ochsner UA. Transient loss of high-level mupirocin resistance in Staphylococcus aureus due to mupA polymorphism. Antimicrob Agents Chemother. 2007;51(6):2247-8.

8. Seah C, Louie L, Simor A, Donald E, Roberto G. MupB, a new high-level mupirocin resistance mechanism in Staphylococcus aureus. Antimicrob Agents Chemother. 2012;56(4):1916-20.

9. Godbeer MS, Gold RM, Lawhon SD. Prevalence of mupirocin resistance in Staphylococcus pseudintermedius. J Clin Microbiol. 2014;52(4):1250-2.

10. Mahmoudi S, Mamishi S, Mohammadi M, Banar M, Ashtiani MT, Mahzari M, et al. Phenotypic and genotypic determinants of mupirocin resistance among Staphylococcus aureus isolates recovered from clinical samples of children: An Iranian hospital-based study. Infect Drug Resist. 2019;12:137-43.

11. Javdan S, Narimani T, Abadi MS, Gholipour A. Agr typing of Staphylococcus aureus species isolated from clinical samples in training hospitals of Isfahan and Shahrekord. BMC Res Notes. 2019;12(1):1-6.

12. Bibalan MH, Shakeri F, Javid N, Ghaemi A, Ghaemi EA. Accessory gene regulator types of Staphylococcus aureus isolated in Gorgan, north of Iran. J Clin Diagn Res. 2014;8(4):DC07-9.

13. Paniagua-Contreras G, Sáinz-Espuñes T, Monroy-Pérez E, Rodríguez-Moctezuma JR, Arenas-Aranda D, Negrete-Abascal E, et al. Virulence markers in Staphylococcus aureus strains isolated from hemodialysis catheters of Mexican patients. Adv Microbiol. 2012;2(04):476-87.

14. Cha JO, Yoo JI, Yoo JS, Chung HS, Park SH, Kim HS, et al. Investigation of biofilm formation and its association with the molecular and clinical characteristics of methicillin-resistant Staphylococcus aureus. Osong Public Health Res Perspect. 2013;4(5):225-32.

15. Magiorakos AP, Srinivasan A, Carey RT, Carmeli Y, Falagas MT, Giske CT, et al. Multidrug-resistant, extensively drug-resistant, and pandrug-resistant bacteria: An international expert proposal for interim standard definitions for acquired resistance. Clin Microbiol Infect. 2012;18(3):268-81.

16. GrinholcM,NakoniecznaJ,NegriA,RapackaZdonczyk A, Motyka A, Fila G, et al. The agr function and polymorphism: impact on Staphylococcus aureus susceptibility to photoinactivation. J Photochem Photobiol B Biol. 2013;129:100-7.

17. Mohajeri P, Gholamine B, Rezaei M, Khamisabadi Y. Frequency of mupirocin resistant Staphylococcus aureus strains isolated from nasal carriers in hospital patients in Kermanshah. Jundishapur J Microbiol. 2012;5(4):560-3.

18. Orrett FA. The emergence of mupirocin resistance among clinical isolates of methicillin-resistant Staphylococcus 
aureus in Trinidad. Jpn J Infect Dis. 2008;61(2):107-10.

19. Fujimura S, Tokue Y, Watanabe A. Isoleucyl-tRNA synthetase mutation in Staphylococcus aureus clinical isolates and in vitro selection of low-level mupirocin-resistant strains. Antimicrob Agents Chemother. 2003;47(10):3373-4.

20. Antonio M, McFerran N, Pallen MJ. Mutations affecting the Rossman fold of isoleucyl-tRNA synthetase are correlated with low-level mupirocin resistance in Staphylococcus aureus. Antimicrob Agents Chemother. 2002;46(2):438-42.

21. Yang JA, Park DW, Sohn JW, Yang IS, Kim KH, Kim MJ. Molecular analysis of isoleucyl-tRNA synthetase mutations in clinical isolates of methicillin-resistant Staphylococcus aureus with low-level mupirocin resistance. J Korean Med Sci. 2006;21(5):827-32.

22. Hesami S, Hosseini SD, AmouzandehNobaveh A, Eskandari S, GhaznaviRad E. Phenotypic and genotypic determination of mupirocin resistance among methicillin susceptibility and resistance in staphylococci isolated from nosocomial infections. J Mazandaran Univ Med Sci. 2014;23(1):30-9.

23. Daskalaki M, Otero JR, Chaves F. Molecular characterization of resistance to mupirocin in methicillin-resistant Staphylococcus aureus isolates in a tertiary hospital in Spain. J Antimicrob Chemother. 2009;63(4):826-8.

24. Chaturvedi P, Singh AK, Shukla S, Agarwal L. Prevalence of mupirocin resistant Staphylococcus aureus isolates among patients admitted to a tertiary care hospital. N Am J Me Sci.2014;6(8):403-7.

25. Saderi H, Oulia P, Habibi M. Detection of resistance to mupirocin in Staphylococcus aureus strains isolated from patients in four university hospitals of Tehran by polymerase chain reaction (pcr) method. Daneshvar Med: Basic Clin Res J. 2008;15(5):31-8.

26. Hadadi M, Heidari H, EbrahimSaraie HS, Motamedifar M. Molecular characterization of vancomycin, mupirocin, and antiseptic resistant Staphylococcus aureus strains. Mediterr J Hematol Infect Dis. 2018;10(1):e2018053. 